\title{
The Association Between Balance and Muscular Strength in Healthy Young Adults
}

\author{
Mariah Gleeson, Mathew Mallet, \& Elise Brown \\ Oakland University, Michigan, USA
}

\begin{abstract}
With aging, there are natural physiological declines, such as decreased neuromuscular function, muscular strength, and balance, often preceding a fall, which is indicated as a public health issue. Nevertheless, young adults do not experience such natural declines as rapidly yet encounter falls that may lead to musculoskeletal injuries. Therefore, the objective of this study was to evaluate the relationship between postural sway and muscular strength in healthy young adults using gold-standard measurements.
\end{abstract}

Keywords: falls, balance, strength

\begin{tabular}{lr}
\hline Article History & $\begin{array}{r}\text { Corresponding Author } \\
\text { Meceived 10 September 2020 }\end{array}$ \\
Accepted 11 October 2020 & mgleeson@oakland.edu \\
Published 31 January 2021 & Deeson \\
Available online 19 February 2021 & Department of Public and Environmental Wellness \\
https://doi.org/10.47544/johsk.2021.2.1.20 & Oakland University, Michigan, USA \\
\hline
\end{tabular}

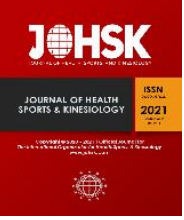

\section{Methods}

The study consisted of thirty-nine healthy adults (mean age $20.8 \pm 2.8$ years, mean body mass $78.4 \pm 17.3 \mathrm{~kg}$.), with no known muscular or bone deficits, uncontrolled medical conditions, high blood pressure, or contraindications to exercise. Static balance was assessed using force plates, measuring vision, vestibular, and proprioception contributions toward balance. Grip strength was assessed using a handgrip dynamometer. After 48 hours, upper and lower body strengths were assessed using a one-repetition maximum bench press and leg press, respectively. To control for effects of body mass on strength, strength measurements were normalized, then transformed into zscores. The average of the z-scores was computed to form a muscular strength index. Pearson correlation coefficients $(r)$ were used to determine the relationship between balance and strength, while controlling for age and sex. The $p$-value was set at $<0.05$.

\section{Results}

A negative moderate correlation was found between the proprioceptive contribution toward balance and normalized handgrip strength $(r=-0.434, p<0.05)$. There were no other significant relationships between postural sway and strength measurements.

\section{Journal of Health, Sports, \& Kinesiology | ISSN 2692-9864 | www.johsk.com}


| 2021 | Volume 2 | Issue 1 | The Journal of Health, Sports, and Kinesiology |

\section{Conclusions}

Our findings indicate that who possess higher handgrip strength may have better balance, however longitudinal studies are needed to determine a causal effect. The lack of association between postural sway and other strength measures suggests that these parameters are independent of each other and may require a separate training form.

(C) 2021. This work is licensed under a CC BY-NC-SA 4.0 International license.

This is an open access article distributed under the Creative Commons Attribution License which permits unrestricted use, distribution, and reproduction in any medium, provided the original work is properly cited.

\section{Journal of Health, Sports, \& Kinesiology | ISSN 2692-9864 | www.johsk.com}

